\title{
Effects of Post-Weld Heat Treatments on the Residual Stress and Mechanical Properties of Electron Beam Welded SAE 4130 Steel Plates
}

\author{
C.C. Huang, Y.C. Pan, and T.H. Chuang
}

\begin{abstract}
The distribution of the residual stresses of electron beam welded SAE 4130 and the effect of stress relief after various post-weld heat treatments (PWHT) were measured using X-ray diffraction. The mechanical properties and microstructure were also examined. Experimental results show that the tensile residual stress increased with the heat input of the electron beam. Most of the residual stresses were relieved by the PWHT at $530^{\circ} \mathrm{C}$ for $2 \mathrm{~h}$ followed by furnace cooling to $50^{\circ} \mathrm{C}$. The strength of the welds decreased slightly, and the elongation of the welds increased after PWHT.
\end{abstract}

\section{Keywords}

electron beam welding, heat treatment, post-weld treatment, residual stress

\section{Introduction}

ELECTRON BEAM welding (EBW) is a high-energy beam welding process. This process utilizes a very high-intensity beam as the power source for welding and has very high penetrating power that a conventional heat source cannot achieve. Because of the extremely concentrated heat source, EBW can produce welds much deeper and narrower than arc welds. In addition to a high depth-to-width ratio, low heat input and minimum distortion of the weld are advantages of EBW.

During welding, thermal stresses occur due to local heating. Residual stresses in a single-pass weld are produced by the resistance of the metal plate to the contraction of the weld. Residual stresses and distortion result after welding and cause mismatching and cracking. In many cases, residual stresses don't cause cracking directly but promote fracturing through fatigue, hydrogen cracking, and stress corrosion. A thorough understanding of the magnitude and distribution of residual stresses can be used to increase the reliability of the structure. Therefore, measurement of residual stresses resulting from various welding parameters is important.

Many methods are used to measure residual stresses, such as stress relief, $x$-ray diffraction (XRD), ultrasound, and the electromagnetic method (including Barkhausen). XRD is the most widely used nondestructive method. The principle is that when a metal is under stress, the resultant elastic strains cause the spacings of atomic planes in the metallic crystal structure to be changed (Ref 1). XRD can measure the interplanar atomic spacing, and from this quantity the stress can be evaluated. Three principal XRD techniques are used for stress measurement: the single-exposure technique, double-exposure technique, and $\sin ^{2} \psi$ method (Ref 2 ). The single-exposure technique requires at least two independent $\mathrm{x}$-ray detectors that

C.C. Huang and T.H. Chuang, Institute of Materials Science and Engineering, National Taiwan University, Taipei, Taiwan, R.O.C.; and Y.C. Pan, Chung Shan Institute of Science and Technology, Lungtan, Taoyuan, Taiwan, R.O.C. can be operated simultaneously. The last two require repositioning of the stress-measuring device or the specimen during the process of performing stress measurement. The $\sin ^{2} \psi$ method is a multi-exposure technique used to promote precision.

Many examples have been given of the application of XRD to measurement of residual stress. Dolle used XRD to measure three-dimensional residual stress states to study the effect of grinding on Armco iron and a medium-carbon steel (Ref 3 ). Ruud used XRD to measure the residual stress on the inside surfaces of stainless steel pipe weldments $(\operatorname{Ref} 4)$. He also used XRD to measure the three-dimensional residual stress field in thick multi-pass steel weldments (Ref 5). Nakayama evaluated the residual stresses in cold-rolled 5083 aluminum alloy by means of XRD (Ref 6). Lu measured the residual stresses for various welding methods using step-by-step hole drilling and XRD (Ref 7). Eigenmann used XRD to measure the residual stresses in thin chromiun coatings on steel ( $\operatorname{Ref} 8$ ). Even the residual stresses of ceramics can be measured by means of XRD (Ref 9).

Residual stresses resulting from welding can be reduced by post-weld heat treatment (PWHT). This result is attributed to the decrease of crystal defects (vacancies and dislocations) and the change of the microstructure. In the present work, residual

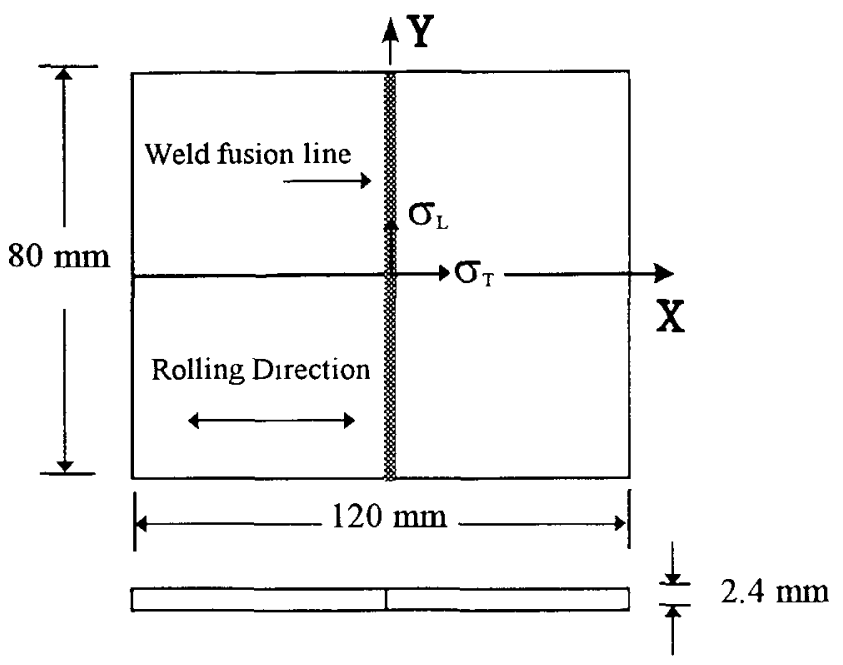

Fig. 1 Schematic illustration of the specimen 
stresses in specimens after EBW under various conditions were measured using XRD. The effects of PWHT on the stress relief and the mechanical properties of electron beam welds were also examined.

\section{Experimental}

The welding specimens were made from SAE 4130 steel plates. The chemical composition of the as-received specimens (wt\%) was $0.31 \mathrm{C}, 0.50 \mathrm{Mn}, 0.91 \mathrm{Cr}, 0.20 \mathrm{Mo}, 0.30 \mathrm{Si}, 0.040 \mathrm{~S}$, $0.035 \mathrm{P}$, and bal Fe. Representive mechanical properties of the material are shown in Table 1 . The dimensions of specimens were $120 \mathrm{~mm} \times 80 \mathrm{~mm} \times 2.4 \mathrm{~mm}$, as shown in Fig. 1. The specimens were welded by means of EBW. The fusion lines of all the weldments were perpendicular to the rolling direction (Fig. 1). EBW was performed under a vacuum of $1 \times 10^{-4}$ torr, with a fixed acceleration voltage of $50 \mathrm{kV}$ and a gun-to-work distance of $53.0 \mathrm{~cm}$. The beam focal point of the electron beam

Table 1 Mechanical properties of the as-received specimens

\begin{tabular}{lcc}
\hline Property & Rolling direction & Transverse direction \\
\hline Tensile strength, $\mathrm{kg} / \mathrm{mm}^{2}$ & 60.1 & 58.7 \\
Yield strength, $\mathrm{kg} / \mathrm{mm}^{2}$ & 37.7 & 34.5 \\
Elongation, $\%$ & 28.7 & 26.3 \\
\hline
\end{tabular}

Table 2 Electron beam welding conditions

\begin{tabular}{lccc}
\hline Parameter & EBW1 & EBW2 & EBW3 \\
\hline Voltage, kV & 50 & 50 & 50 \\
Current, mA & 90 & 60 & 35 \\
Power, kW & 4.5 & 3 & 1.75 \\
Welding speed, & 2032 & 1524 & 1016 \\
$\quad$ mm/min & 0.1333 & 0.118 & 0.103 \\
Energy, kJ/mm & & \\
Note: The gun-to-work distance of EBW was $530 \mathrm{~mm}$. & \\
\hline
\end{tabular}

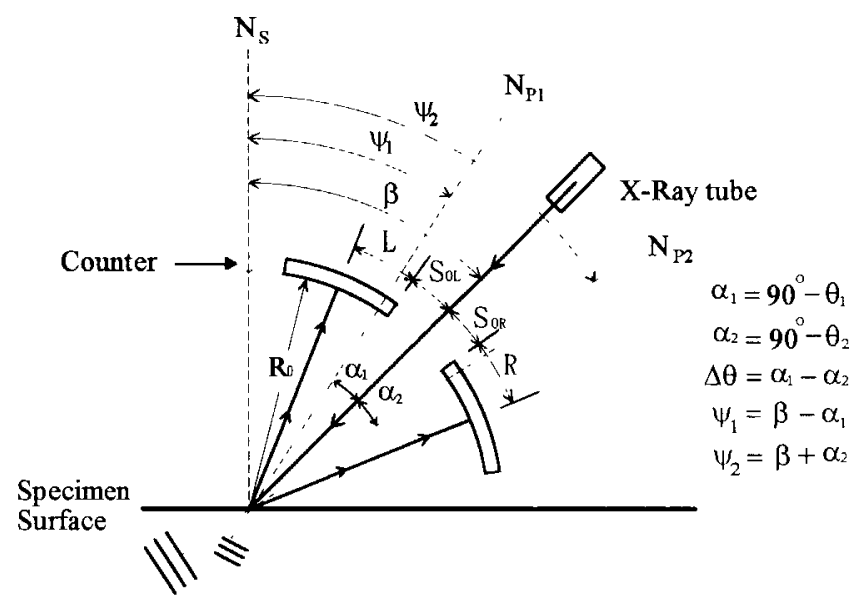

Fig. 2 An illustration of the single-exposure technique. See Eq 1 and 2 for definition of symbols. welds was stationed $0.2 \mathrm{~mm}$ above the work surfaces. The welding conditions are shown in Table 2.

Stress analyses were performed by using a proto XRD-1000 diffractometer with one $x$-ray tube and two position-sensitive scintillation detectors (PSSD) (Ref 10). It can be operated using the single-exposure technique, double-exposure technique, or multi-exposure technique. The geometrical relationship of
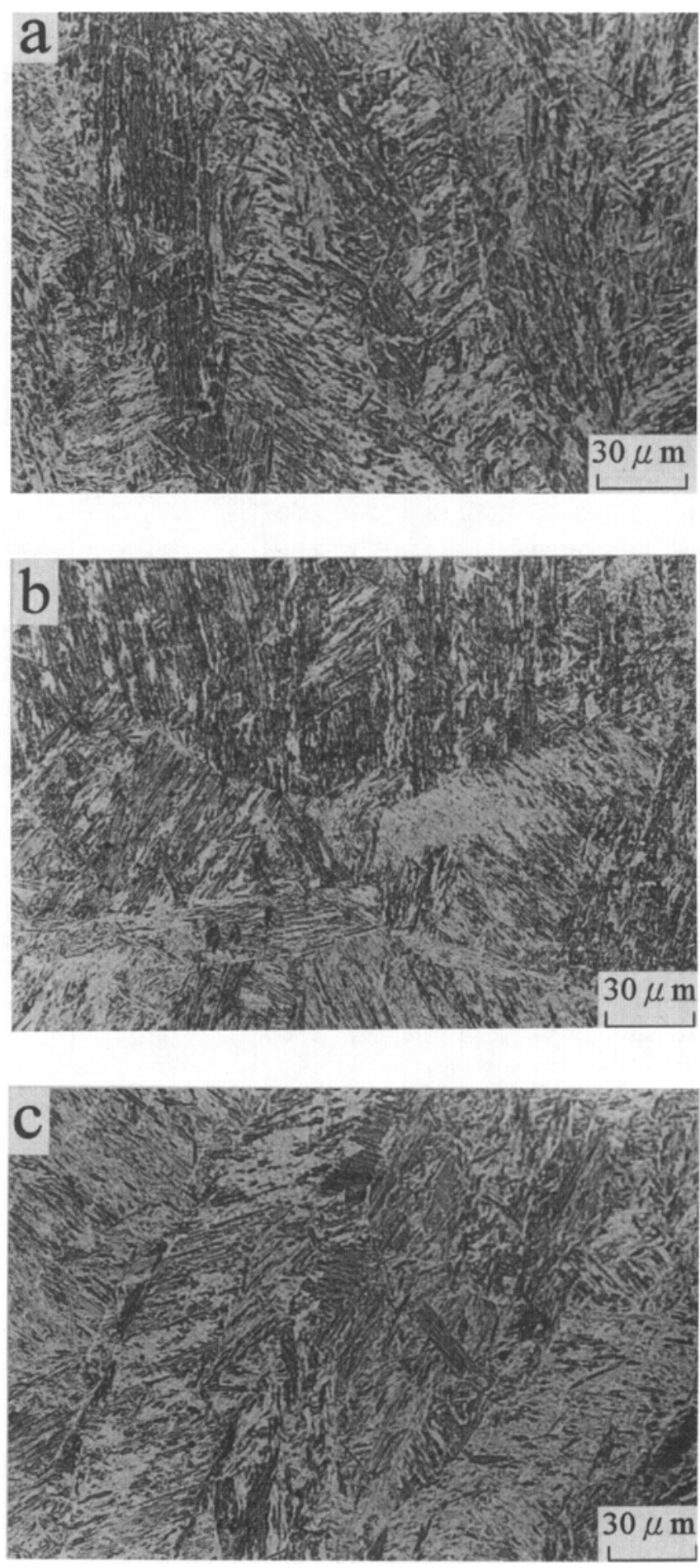

Fig. 3 Metallographs of the weld metal for: (a) EBW 1, (b) EBW2, (c) EBW3 
the single-exposure technique is shown in Fig. 2. For the single-exposure technique, the residual stresses are calculated from:

$$
\sigma_{\varphi}=\frac{E\left[(R-L)+\left(S_{\mathrm{OR}}-S_{\mathrm{OL}}\right)\right]}{4 R_{0}(1+v) \sin ^{2} \theta \sin 2 \beta}
$$
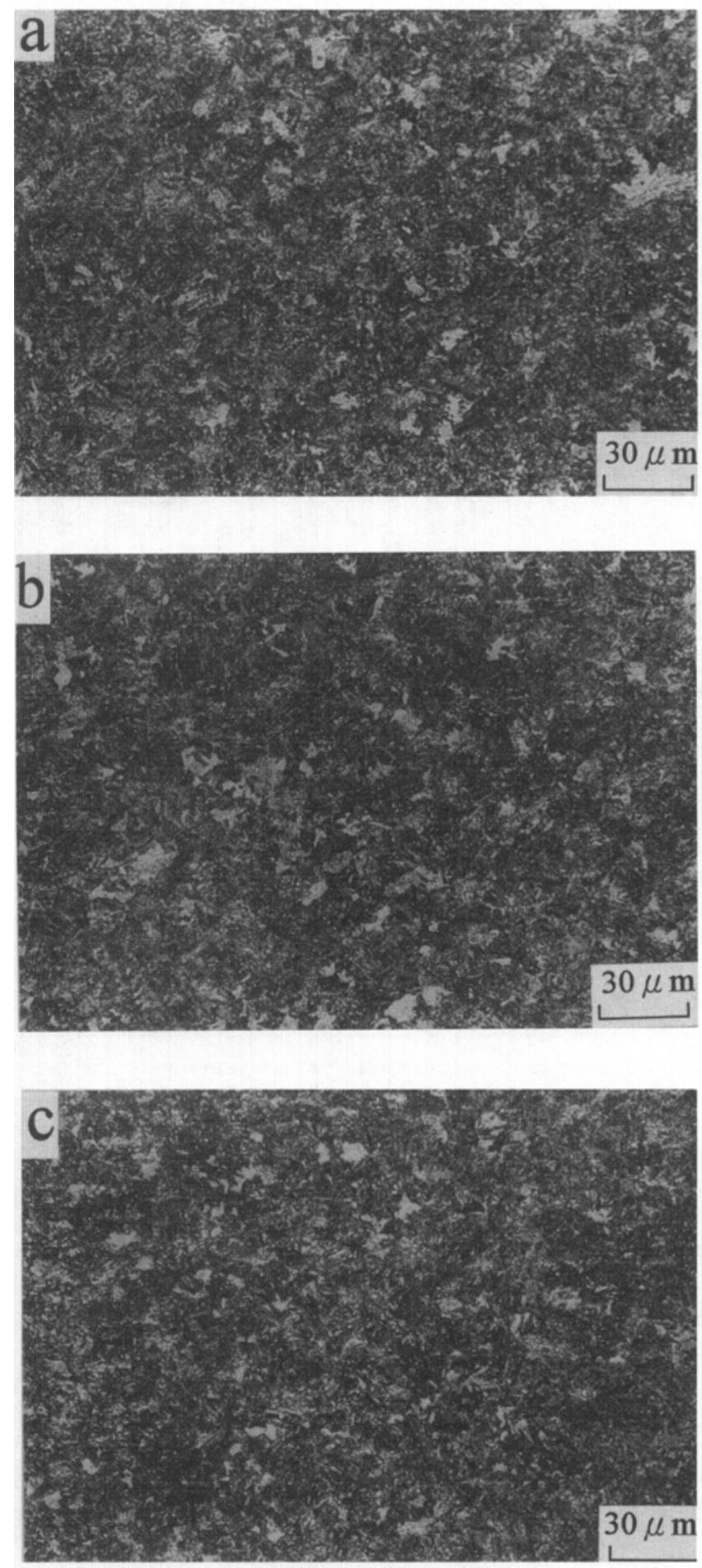

Fig. 4 Metallographs of the HAZ for: (a) EBW1, (b) EBW2, (c) EBW3 where $E$ is Young's modulus, $v$ is Poisson's ratio, $R_{0}$ is the distance between the counter and the specimen surface, $\beta$ is the angle between the normal of the specimen surface and the $\mathrm{x}$-ray tube, $R$ and $L$ are the distances between the diffraction lines and the edges of the counters, and $S_{\mathrm{OR}}$ and $S_{\mathrm{OL}}$ are the arc lengths from the incident beam to the inside edges of the counters.
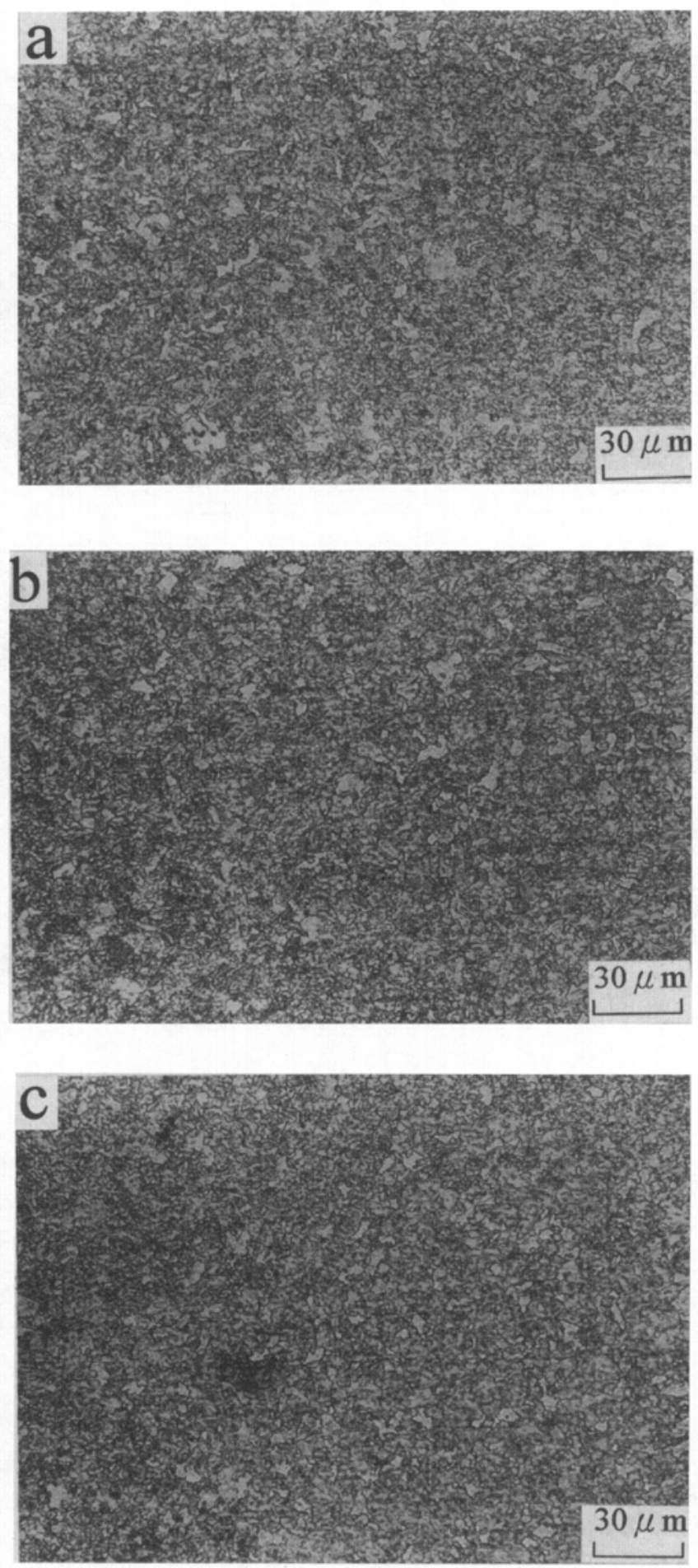

Fig. 5 Metallographs of the transition region between the HAZ and the base metal for: (a) EBW1, (b) EBW2, (c) EBW3 
For the double-exposure technique, the residual stresses can be calculated from the difference of the two diffraction angles, $\Delta \theta$ :

$$
\sigma_{\varphi}=\frac{E}{(1+v)} \frac{\cot \theta \Delta \theta}{\sin ^{2} \psi}
$$
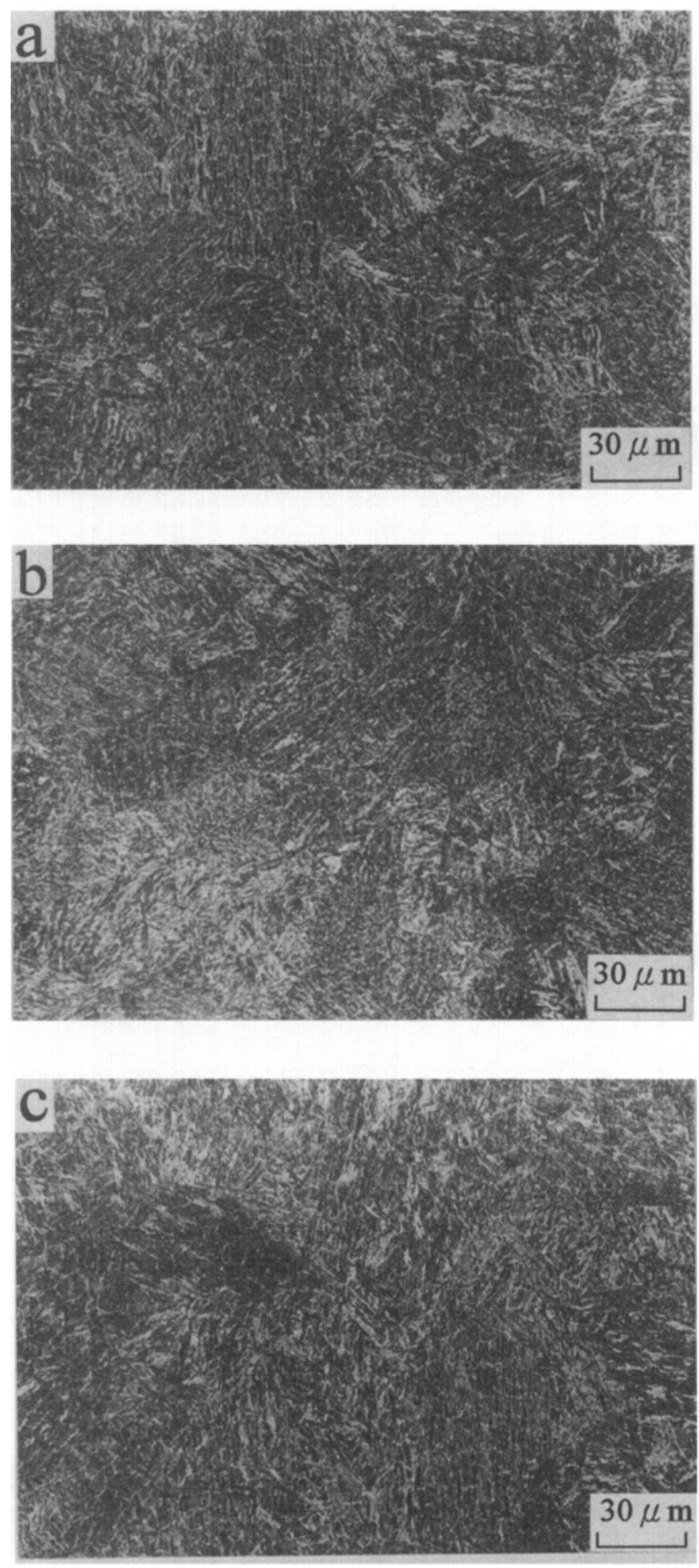

Fig. 6 Metallographs of the weld metal for: (a) EBW 1, (b) EBW2, (c) EBW3 after PWHT at $320{ }^{\circ} \mathrm{C}$ for $2 \mathrm{~h}$ where $\theta$ is the diffraction angle and $\psi$ is the angle between the normal of the lattice plane $\left(N_{\mathrm{p}}\right)$ and that of the specimen surface $\left(N_{\mathrm{S}}\right)$.

The multi-exposure technique is used to promote precision. Measurements are made at a number of angles rather than at only one. Equation 2 can be rewritten as:

$$
\Delta \theta=\frac{(1+v) \sigma_{\varphi}}{E \cot \theta} \sin ^{2} \psi
$$

Values of $\Delta \theta$ are plotted against $\sin ^{2} \psi$, and the stress $\sigma_{\varphi}$ is derived from the slope of the line. The more points there are, the more precisely the line will be established.

In the present work, the multi-exposure technique was used for stress measurement. Measurements were made with $\mathrm{CrK}_{\alpha}$ radiation to examine the [211] Bragg reflection plane and obtain a diffraction line at $2 \theta=156^{\circ}$ for the unstressed condition. $\mathrm{CrK}_{\alpha}$ was excited at $25 \mathrm{kV}$ and $5 \mathrm{~mA}$. Eight $\beta$ tilts were examined : $\pm 2^{\circ}, \pm 10^{\circ}, \pm 20^{\circ}$, and $\pm 45^{\circ}$. The values used for the other constants were $R_{0} \cong 40 \mathrm{~mm}, E /(1+v)=156,000 \mathrm{MPa}$. The stress measurements were conducted along the transverse line passing through the weld center (the $x$ axis in Fig. 1) and the longitudinal line parallel to the weld edge. Because the specimens were semisymmetric, only the stresses of the right halves were measured.

In order to evaluate the effect of PWHT on the welding residual stresses relief, the welded specimens were heated to 320 and $530^{\circ} \mathrm{C}$ for $2 \mathrm{~h}$ and then furnace cooled to $50^{\circ} \mathrm{C}$. The residual stresses of the PWHT specimens were measured following the same process. The welded specimens were then sectioned and prepared for metallographic inspections and microhardness measurements. The tensile properties of the welds were determined at room temperature using an MTS machine. Tensile specimens were made in accordance with ASTM E8M-93 with a gage length of $25 \mathrm{~mm}$.

\section{Results and Discussion}

The weldments of the as-welded SAE 4130 steel possessed a coarse lath martensite structure, as shown in Fig. 3. The structures of the heat-affected zones (HAZ) are shown in Fig. 4. All of them were fine-grain martensite containing solid solutions of $\alpha-\mathrm{Fe}$. The structure of the transition region between the base metal and HAZ was a mixture of fine-grain martensite which contained solid solutions of $\alpha-\mathrm{Fe}$ and retained ferrite, as shown in Fig. 5. The metallographs of the electron beam welds under various weld conditions were similar to one another. The structure of the welds transformed to tempered martensite after both PWHTs (at 320 and $530^{\circ} \mathrm{C}$ ) are shown in Fig. 6 and 7, respectively. As the temperature of PWHT increased, the precipitation of $\alpha-\mathrm{Fe}$ also increased.

The stresses measured in the welds were the longitudinal residual stress $\sigma_{\mathrm{L}}$ and the transverse residual stress $\sigma_{\mathrm{T}}$, as shown in Fig. 1. Figure 8(a) presents the residual stresses along an axis perpendicular to the weld measured on the surfaces of the EBW specimens under different welding conditions. The sequence of heat input for various weld conditions is: EBW1 $>$ EBW2 > EBW3. Figure 8(a) also shows that the sequence of $\sigma_{L}$ in the 
tension zone of the welds corresponded to the sequence of heat input: EBW1 $>$ EBW2 $>$ EBW3. This result implies that $\sigma_{\mathrm{L}}$ in the tension zone is proportionally related to the heat input. Not only $\sigma_{\mathrm{L}}$, but also $\sigma_{\mathrm{T}}$, taken $1 \mathrm{~cm}$ from the weld center line, was converted into compressive stresses. From Fig. 8(a), it can also be seen that $\sigma_{T}$ was far less than $\sigma_{\mathrm{L}}$ in the tension zone. How-
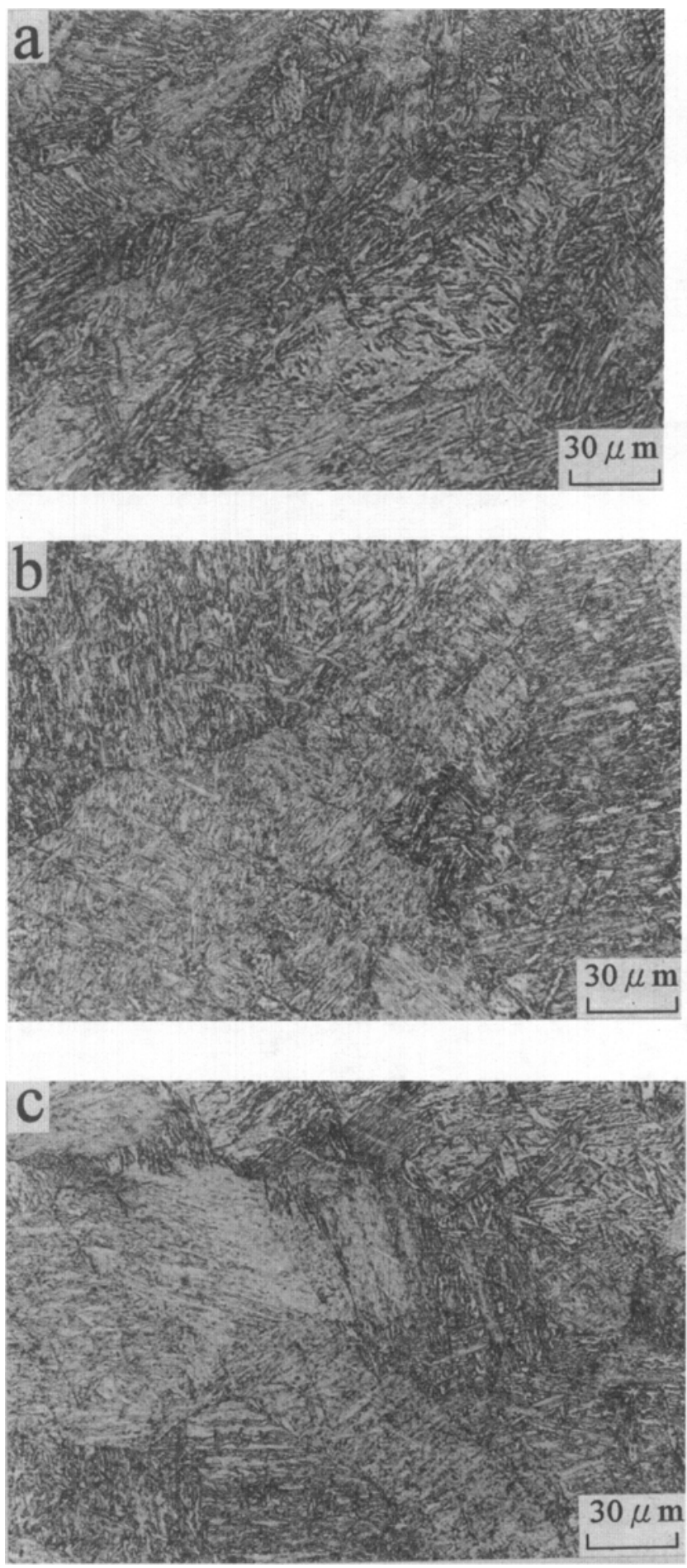

Fig. 7 Metallographs of the weld metal for: (a) EBW1, (b) EBW2, (c) EBW3 after PWHT at $530^{\circ} \mathrm{C}$ for $2 \mathrm{~h}$ ever, there was no obvious relation between $\sigma_{\mathrm{T}}$ and heat input for the three specimens.

The residual stress distributions along the line parallel to the weld fusion line and close to the weld edge for the EBW specimens are shown in Fig. 8(b). The longitudinal residual stresses were nearly constant in the middle sections of the welds and were reduced near the ends of the welds. The transverse residual stresses were very small in the middle sections of the welds and were converted into compressive stresses near the ends of
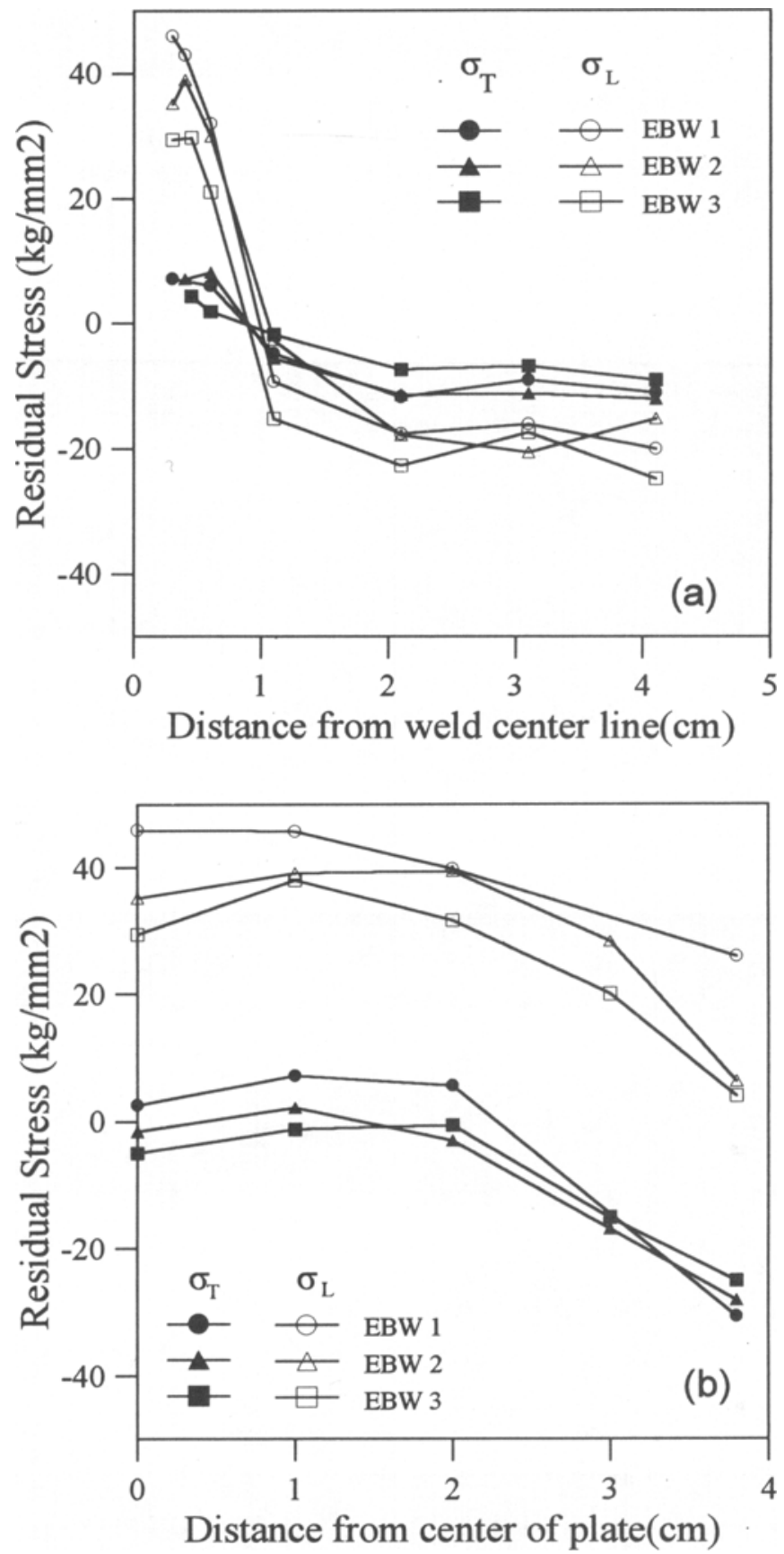

Fig. 8 The distribution of residual stresses along: (a) the transverse line passing through the weld center and (b) the longitudinal line parallel and close to the weld edge for electron beam welds 
the welds. All the longitudinal residual stresses of the three specimens were larger than their transverse residual stresses. The quantitative sequence of $\sigma_{\mathrm{L}}$ also corresponded to the sequence of heat input. In the middle sections of the welds, the quantitative sequence of $\sigma_{\mathrm{T}}$ for various weld conditions was similar to that of $\sigma_{\mathrm{L}}$. Near the ends of the welds, $\sigma_{\mathrm{T}}$ was converted into compressive stresses, and the sequence of $\sigma_{\mathrm{T}}$ was reversed.
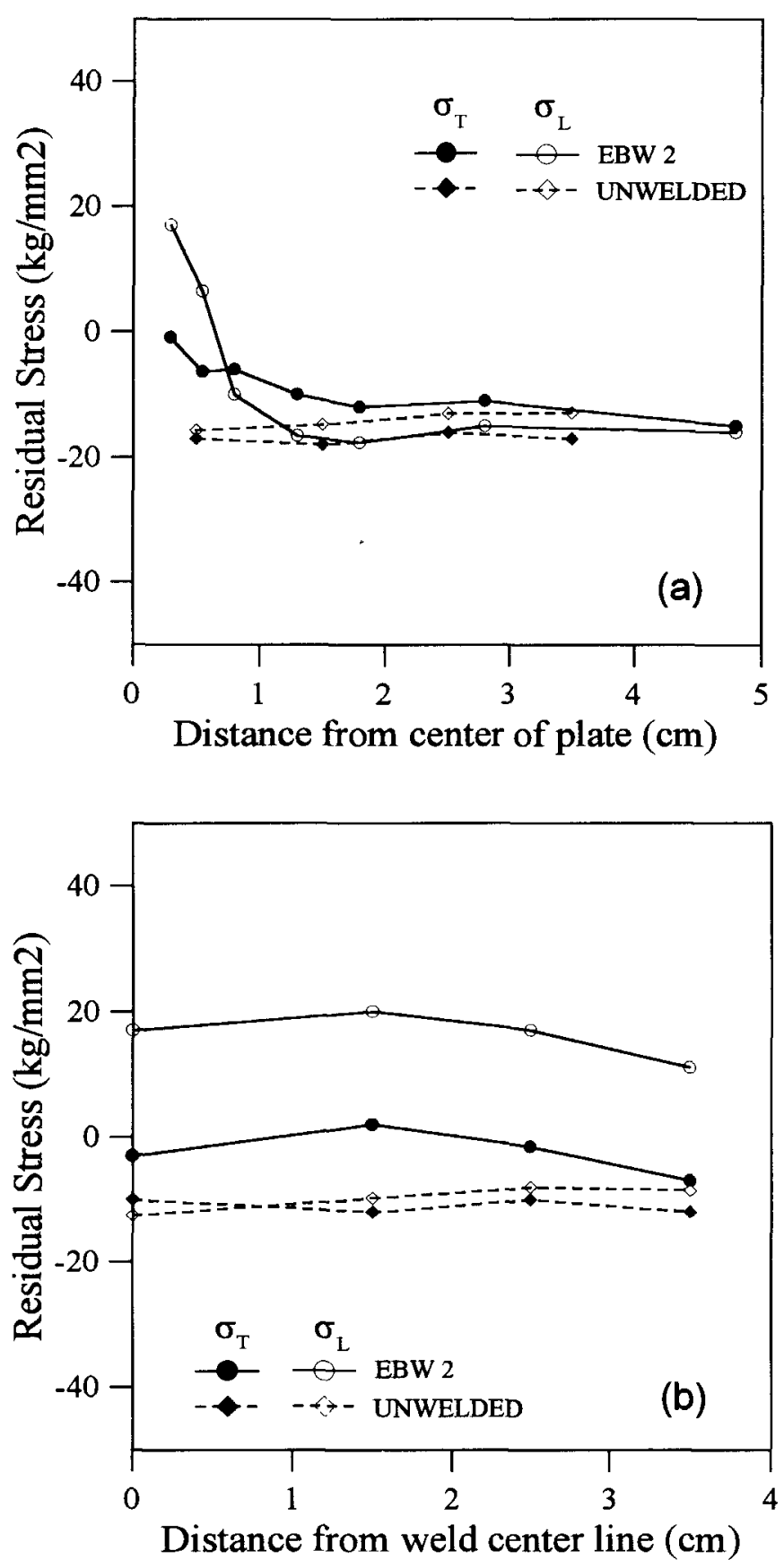

Fig. 9 The distribution of residual stresses along: (a) the transverse line passing through the weld center and (b) the longitudinal line parallel and close to the weld edge for specimens after PWHT at $320^{\circ} \mathrm{C}$ for $2 \mathrm{~h}$
The distributions of the residual stresses for the specimens after PWHT are shown in Fig. 9 and 10. For comparison, the stresses of the unwelded specimens are also presented. The residual stresses were partially relieved after PWHT at $320^{\circ} \mathrm{C}$, as shown in Fig. 9. The $\sigma_{\mathrm{L}}$ in the tension zone as shown in Fig. 9(a) and the $\sigma_{L}$ as shown in Fig. 9(b) decreased, but they were still tensile stresses. Since the magnitude of $\sigma_{\mathrm{T}}$ for the aswelded specimen was small, the variation of $\sigma_{\mathrm{T}}$ after PWHT at
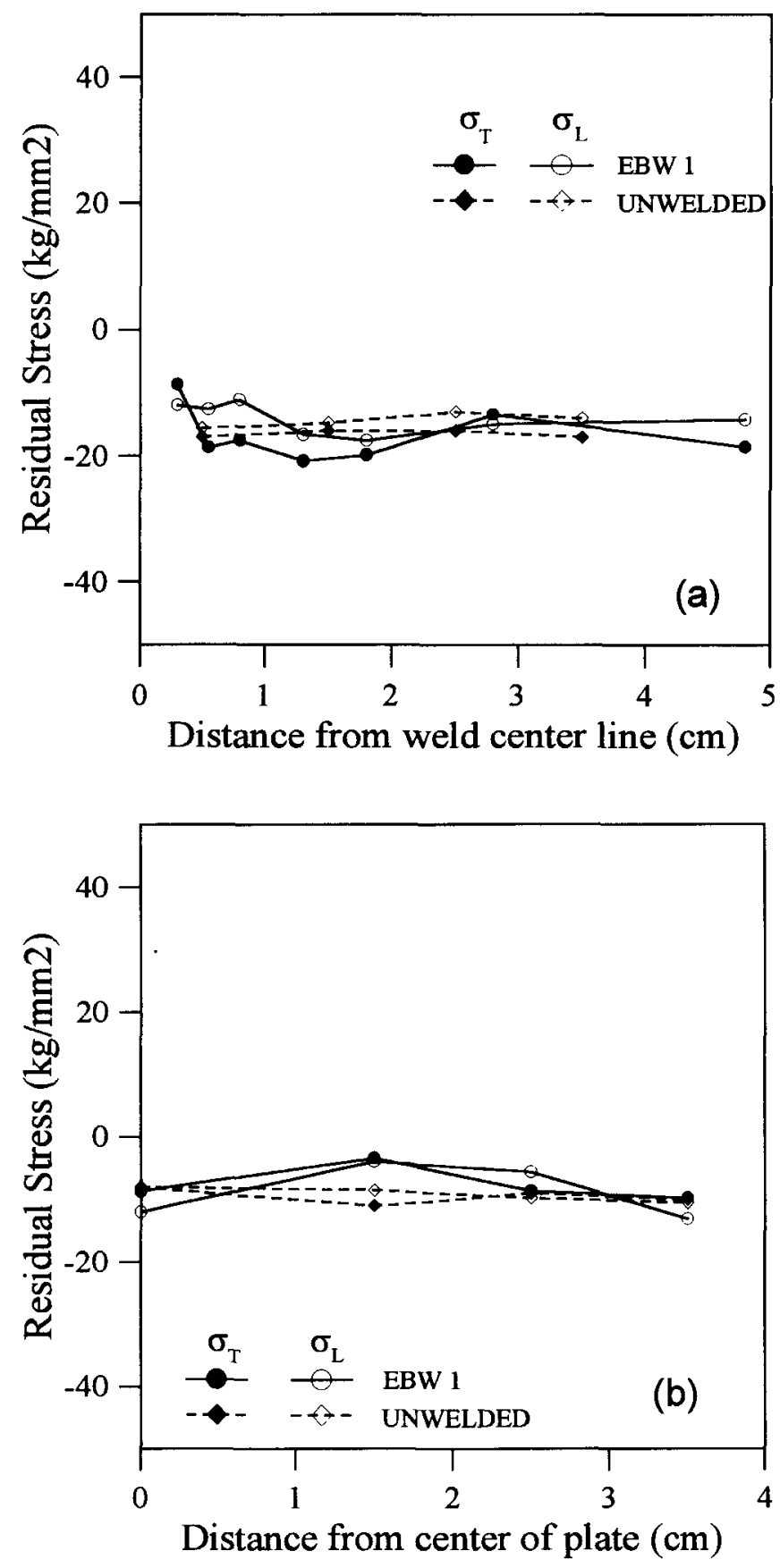

Fig. 10 The distribution of residual stresses along: (a) the transverse line passing through the weld center and (b) the longitudinal line parallel and close to the weld edge for specimens after PWHT at $530^{\circ} \mathrm{C}$ for $2 \mathrm{~h}$ 
$320^{\circ} \mathrm{C}$ was not obvious. The stress relief effect was complete after PWHT at $530^{\circ} \mathrm{C}$, as shown in Fig. 10. Fig. 10(a) shows that there were no tensile residual stresses in the original tension zone. The magnitudes of $\sigma_{\mathrm{T}}$ and $\sigma_{\mathrm{L}}$ were close to those of the unwelded specimen, as shown in Fig. 10(b). The mechanical properties of the welds before and after various PWHTs are summarized in Table 3. For comparison, the mechanical properties of the base metal are also listed in the table. It seems that the strength of the as-welded specimens decreased slightly and that the elongation increased as the heat input of EBW increased. The yield strength of the welds increased after PWHT at $320^{\circ} \mathrm{C}$, but that of the welds decreased as the temperature of PWHT increased to $530^{\circ} \mathrm{C}$. In order to compare the differences among the mechanical properties for various PWHTs, Table 4 and Fig. 11 are given. The loss of yield strength decreased when the temperature of the PWHTs increased, as shown in Fig. 11(a). The joint efficiency was scarcely different after PWHT at $320^{\circ} \mathrm{C}$, but it increased after PWHT at $530^{\circ} \mathrm{C}$, as shown in Fig. 11 (b). The loss of elongation was reduced as the

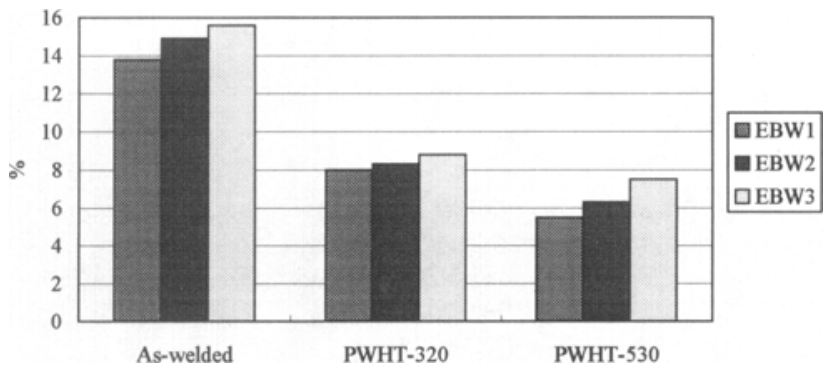

(a)

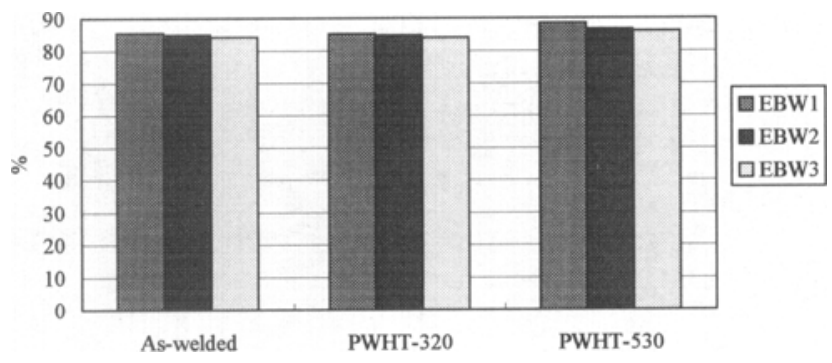

(b)

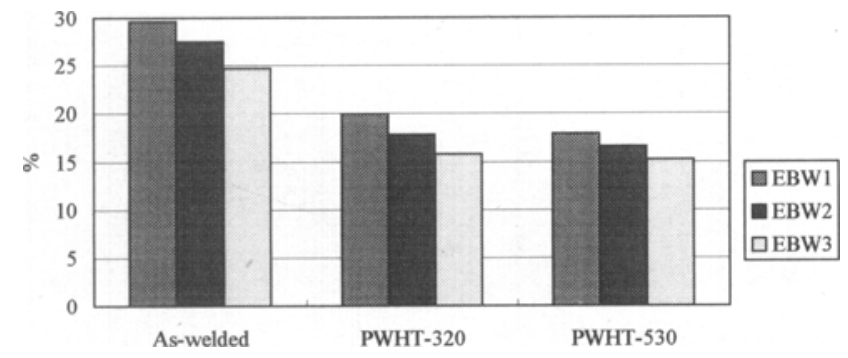

(c)

Fig. 11 Comparisons of the mechanical properties for aswelded specimens, PWHT at $320^{\circ} \mathrm{C}$ (PWHT-320) or $530^{\circ} \mathrm{C}$ (PWHT-530). (a) Loss of yield strength. (b) Joint efficiency. (c) Loss of elongation temperature of PWHT increased, as shown in Fig. 11(c). It is obvious that the mechanical properties of the welds could be improved after PWHTs, and that the improvement effect for PWHT at $530^{\circ} \mathrm{C}$ was better than that at $320^{\circ} \mathrm{C}$.

The microhardness measurements on the as-welded and post-weld heat treated EBW specimens are shown in Fig. 12. All of the microhardness profiles are similar. Since the structure of the welds was martensite, the hardness of the welds was much larger than that of the base metal. There was a drastic drop in hardness for the weld across the HAZ. After PWHT at $320^{\circ} \mathrm{C}$, the hardness of the welds obviously decreased and that of the base metal decreased slightly. After PWHT at $530^{\circ} \mathrm{C}$, the hardness of the welds decreased further. The decrease of hardness in the weld region was obviously attributable to the change

Table 3 Mechanical properties of the welds after various PWTHs

\begin{tabular}{lccc}
\hline PWHT & $\begin{array}{c}\text { YS, } \\
\mathbf{k g} / \mathbf{m m}^{2}\end{array}$ & $\begin{array}{c}\text { UTS, } \\
\mathbf{k g} / \mathbf{m m}^{2}\end{array}$ & $\begin{array}{c}\text { Elongation, } \\
\text { \% }\end{array}$ \\
\hline As-welded & & & \\
Base & 37.7 & 60.1 & 28.7 \\
EBW1 & 32.5 & 51.4 & 20.2 \\
EBW2 & 32.1 & 51.0 & 20.8 \\
EBW3 & 31.8 & 50.6 & 21.6 \\
320 ${ }^{\circ}$ C, 2 h, F.C. & & & \\
Base & 37.3 & 59.8 & 29.2 \\
EBW1 & 34.3 & 51.0 & 23.4 \\
EBW2 & 34.2 & 50.7 & 24.0 \\
EBW3 & 34.0 & 50.3 & 24.6 \\
530 ${ }^{\circ}$ C, 2 h, F.C. & & & \\
Base & 34.8 & 56.9 & 30.2 \\
EBW1 & 329 & 503 & 24.8 \\
EBW2 & 32.6 & 49.3 & 25.2 \\
EBW3 & 32.2 & 49.0 & 25.6
\end{tabular}

Note: All specimens were tensile fractured in the base metal. YS, yield strength; UTS, ultimate tensile strength. F.C. is furnace cooling to $50^{\circ} \mathrm{C}$.

Table 4 The loss of mechanical properties for the welds after various PWHTs

\begin{tabular}{lccc}
\hline PWHT & $\begin{array}{c}\text { Loss of YS, Loss of elongation, } \\
\%\end{array}$ & & Joint efficiency(a), \\
\hline As-welded & & 29.6 & 85.5 \\
EBW1 & 13.8 & 27.5 & 84.9 \\
EBW2 & 14.9 & 24.7 & 84.2 \\
EBW3 & 15.6 & & 85.3 \\
320 ${ }^{\circ}$ C, 2 h, F.C. & & 19.9 & 84.8 \\
EBW1 & 8.0 & 17.8 & 84.1 \\
EBW2 & 8.3 & 15.8 & 88.4 \\
EBW3 & 8.8 & 179 & 866 \\
530 ${ }^{\circ}$ C, 2 h, F.C. & & 16.6 & 86.1 \\
EBW1 & 5.5 & 15.2 & \\
EBW2 & 6.3 & & \\
EBW3 & 7.5 & & \\
& & & \\
(a) Ultimate tensile strength of the weld/ultimate tensile strength of the \\
base metal. YS, yield strength. F.C. is furnace cooling to $50^{\circ} \mathrm{C}$. \\
\hline
\end{tabular}



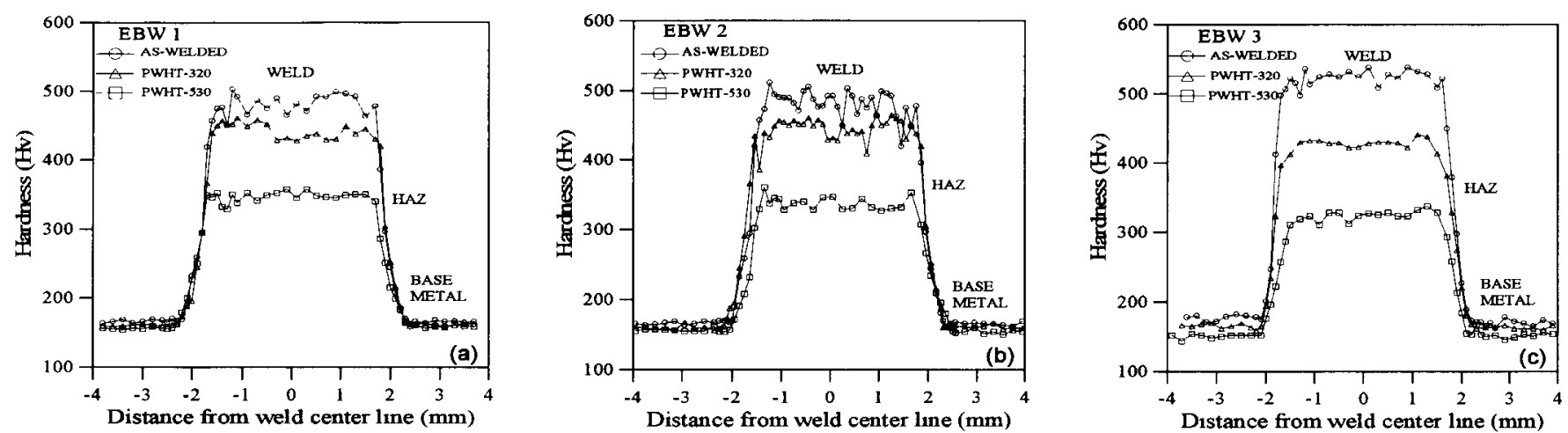

Fig. 12 Microhardness profiles on as-welded specimens, PWHT at $320^{\circ} \mathrm{C}$ (PWHT-320) or $530^{\circ} \mathrm{C}$ (PWHT-530). (a) EBW1. (b) EBW2. (c) EBW3

of structure from coarse lath martensite to tempered martensite after PWHT.

\section{Conclusions}

There were very narrow tension zones along the transverse direction for the EBW specimens. With the increase of the heat input of the electron beam weld, the $\sigma_{\mathrm{L}}$ in the tension zone along the line perpendicular to the weld and passing through the weld center was larger. There were similar results for $\sigma_{L}$ and $\sigma_{\mathrm{T}}$ along the line parallel to the weld fusion line and close to the weld edge for the electron beam welds. As the temperature of PWHT increased from 320 to $530^{\circ} \mathrm{C}$, the effect of stress relief became more obvious. Heat treatment at $530^{\circ} \mathrm{C}$ for $2 \mathrm{~h}$ and furnace cooling to $50^{\circ} \mathrm{C}$ could most effectively relieve the residual stresses of the EBW specimens. Corresponding to the stress-relief effect, the mechanical properties were improved. Although the strength of the welds decreased slightly, the elongation of the welds obviously increased after PWHT. PWHT also caused the hardness of the welds to decrease. The effect of PWHT on the residual stress and mechanical properties was at- tributed to the change of microstructure in the weldments from coarse lath martensite to tempered martensite.

\section{References}

1. C.S. Choi, H.J. Prask, and S.F. Trovino, Journal of Applied Crystallography, Vol 12, 1979, p 327

2. Residual Stresses Measurement by X-Ray Diffraction, 2nd ed., SAE J784a, Society of Automotive Engineers, 1971, p 17-24

3. H. Dolle and J.B. Cohen, Metall. Trans., Vol 11A, 1980, p 159164

4. C.O. Ruud, P.S. DiMascio, and D.M. Melcher, Experimental Mechanics, Vol 24 (No. 2), 1984, p 162-168

5. C.O. Ruud, R.N. Pangborn, P.S. DiMascio, and D.J. Snoha, Journal of Pressure Vessel Technology, Vol 107, 1985, p 185-191

6. Y. Nakayama, T. Takaai, and S. Kimura, Materials Tractions, Vol 34 (No. 6), 1993, p 496-503

7. J. Lu, C. Bouhelier, H.P. Lieurade, D. Baralle, B. Miege, and J. F. Flavenot, Welding in the World, Vol 33 (No. 2), 1994, p 118-128

8. B. Eigenmann, B. Scholtes, and E. Macherauch, Surface Engineering, Vol 7 (No. 3), 1991, p 221 - 224

9. C.O. Ruud and C.P. Gazzara, J. Am. Ceram. Soc., Vol 68 (No. 2), $1985, p$ 67-68

10. C.O. Ruud, Industrial Research and Development, Jan 1983, p 84.87 